\title{
REFLEXIONES JURÍDICAS EN TIEMPOS DEL COVID-19: "LA FUERZA MAYOR SE HIZO VIRAL"
}

\author{
LUCIANO BARCHI VELAOCHAGA \\ Universidad de Lima, Lima, Perú \\ Recibido: 10/8/2020 - Aprobado: 17/8/2020 \\ doi: https://doi.org/10.26439/iusetpraxis2020.n50-51.5035
}

\begin{abstract}
RESUMEN. Ante la inmovilización ocasionada por la pandemia del COVID-19, se ha hecho bastante frecuente la invocación de la fuerza mayor como un hecho impeditivo para el cumplimiento de las obligaciones en los contratos. El autor analiza los elementos que constituyen la fuerza mayor, las clases de fuerza mayor, los supuestos a los que aplica y el concepto de imposibilidad sobreviniente por causa no imputable a las partes. También efectúa un análisis de la atribución de responsabilidad entre las partes cuando la prestación se torna imposible y si la fuerza mayor puede ser un eximente de responsabilidad.
\end{abstract}

PALABRAS CLAVE: fuerza mayor / extraordinario / imprevisible / irresistible / imposibilidad sobreviniente / causa no imputable / impedimento

\section{LEGAL CONSIDERATIONS IN TIMES OF COVID-19: "FORCE MAJEURE HAS GONE VIRAL"}

ABSTRACT. Due to the social lockdown caused by the COVID-19 pandemic, invocation of force majeure as an event that frustrates the performance of the obligations in a contract has become commonplace. The author analyzes the elements that make up the concept of force majeure, the types of force majeure, the cases in which it can be applied, and the notion of impossibility because of non-attributable cause. He also examines the attribution of liability between the parties of a contract when the obligations of said contract become impossible, and ponders if force majeure can free the parties of liability.

KEYWORDS: force majeure / extraordinary / unpredictable / irresistible / impossibility / non-attributable cause / impediment 
El cólera se le convirtió en una obsesión. No sabía de él mucho más de lo aprendido de rutina en algún curso marginal, y le había parecido inverosímil que solo treinta años antes hubiera causado en Francia, inclusive en París, más de ciento cuarenta mil muertos.

Gabriel García Márquez

El amor en los tiempos del cólera

\section{INTRODUCCIÓN: EL ESTADO DE LA CUESTIÓN}

El 15 de marzo del 2020 se publicó en el diario oficial El Peruano el Decreto Supremo 044-2020-PCM, que declaró el estado de emergencia nacional por el plazo de quince días calendario y dispuso el aislamiento social obligatorio (cuarentena) por las graves circunstancias que afectaron la vida de la nación a consecuencia del brote del COVID-19.

Durante el estado de emergencia nacional, se garantizó el abastecimiento de alimentos y medicinas, así como la continuidad de los servicios de agua, saneamiento, energía eléctrica, gas, combustible, telecomunicaciones, limpieza y recojo de residuos sólidos, servicios funerarios y otros establecidos en dicho decreto supremo. Esto supuso la continuación de las actividades de las empresas que prestan los servicios antes señalados e, implícitamente, la suspensión legal de las demás actividades empresariales.

De inmediato se produjo una avalancha de invocaciones de fuerza mayor en el seno de diferentes tipos de contratos, sea porque se consideraba al COVID-19 como un hecho "extraordinario, imprevisible e irresistible" (hecho de Dios), sea porque se consideraba que tales características correspondían al Decreto Supremo 044-2020-PCM (hecho del príncipe). Esta ponencia recoge algunas de tales divagaciones.

\section{LA FUERZA MAYOR: LA DENOMINACIÓN}

En Roma se hablaba de vis major o vis divina. El artículo 1315 del Código Civil define al caso fortuito o la fuerza mayor (en adelante, FM) como un evento "extraordinario, imprevisible e irresistible". El caso fortuito hace referencia a los "hechos de Dios" y la FM a los "hechos del príncipe", pero se reconoce que poseen iguales características-(Osterling, 2007). En el derecho anglosajón se habla de force majeure, expresión tomada del francés.

\section{LAS CARACTERÍSTICAS DE LA FUERZA MAYOR EN EL CÓDIGO CIVIL PERUANO}

El artículo 1315 del Código Civil señala: "Caso fortuito o fuerza mayor es la causa no imputable, consistente en un evento extraordinario, imprevisible e irresistible, que impide la ejecución de la obligación o determina su cumplimiento parcial, tardío o defectuoso". 
El artículo citado considera como elemento de la calificación de la FM el carácter extraordinario, imprevisible e irresistible del evento. Bajo el Código Civil francés, los tres elementos necesarios que deben presentarse - acumulativamente- para que un evento califique como FM son la exterioridad, la imprevisibilidad y la irresistibilidad (Antonmattei, 1992, p. 12).

\section{a) Extraordinario}

Nuestro Código Civil hace referencia a "extraordinario"; sin embargo, bajo el Código Civil francés no se menciona esta característica: se habla de "exterioridad" (extériorité) (Larroumet, 1993, p. 167). Externo, es decir, fuera de la esfera de control del deudor; así, por ejemplo, los actos de Dios (acts of God), los actos de guerra (acts of war), entre otros. De Trazegnies (2015) señala que "extraordinario" es algo que sale de lo "ordinario, que no se ajusta a la sucesión normal de hechos" (p. 90).

En referencia a la "exterioridad" (extériorité) del evento, hoy es frecuente utilizar la expresión "impedimento ajeno a su control" o beyond the control of the parties.

\section{b) Imprevisible}

Además de extraordinario, el evento debe ser imprevisible para el deudor en el momento de celebrar el contrato. La imprevisibilidad del evento ha de ser apreciada in abstracto, es decir, se debe determinar si era previsible para un "hombre razonable" (Larroumet, 1993, p. 169) al momento de la celebración del contrato.

De acuerdo con Roppo (2011), el juicio de previsibilidad juega esencialmente sobre dos datos: el grado de especificidad y el grado de probabilidad del hecho sobrevenido a los cuales referir la posibilidad de preverlo. Más alto el grado de especificidad que se asume, más fácilmente el hecho deberá considerarse imprevisible: es previsible la genérica posibilidad de que en el futuro haya guerras; un poco menos previsible entre qué países estallará la guerra, y todavía menos previsible - diríase imprevisibleque la guerra estallará en los próximos diez días y que como consecuencia de ella se producirá la clausura, por ejemplo, del canal de Suez (p. 1025).

c) Irresistible

Irresistible es aquello a lo que uno no se puede oponer. Larroumet (1993) señala lo siguiente:

Lo mismo que la imprevisibilidad, la irresistibilidad se aprecia in abstracto, esto es, por referencia a lo que una persona normalmente razonable está en condiciones de hacer para evitar las consecuencias de un acontecimiento cuya ocurrencia no pudo evitar. En efecto, la irresistibilidad se aplica al acontecimiento mismo, o sea que ella supone que el deudor no pudo impedir que el acontecimiento ocurriera [...], pero se aplica también a las consecuencias del acontecimiento, esto es, que la ocurrencia de este debe haber impedido absolutamente al deudor ejecutar su obligación. (p. 171) 


\section{LAS CLÁUSULAS DE FUERZA MAYOR EN LOS CONTRATOS}

La dificultad para establecer claramente el sentido de las características de la FM les da a los jueces (y a los árbitros) un considerable margen de discreción al evaluar su presencia. Esto lleva a las partes a incluir en los contratos — cada vez con mayor frecuencia-una cláusula que defina la FM (force majeure clauses). Se recurre a una práctica común en los países del common law y de los contratos internacionales. Al respecto, Katsivela (2007) señala lo siguiente: “Force majeure clauses that excuse a breaching party from liability for non-performance are common in most legal systems and are almost invariably included in international business contracts" (p. 110).

En el Perú, hay contratos a los que se aplica la ley peruana que contienen este tipo de cláusulas - propias del sistema del common law-. De Nova (2010), en Italia, habla del contratto alieno (contrato ajeno) para referirse a aquellos contratos regulados bajo la ley de un país del civil law en los que se incorporan cláusulas diseñadas para el sistema del common law (p. 2).

En tal sentido, determinar las características del evento que constituye FM dependerá de si se aplica supletoriamente el artículo 1315 del Código Civil (extraordinario, imprevisible e irresistible) o de si el contrato contiene una cláusula de FM (en cuyo caso las características de la FM dependerán de lo que las partes hayan acordado). Se distingue así entre force majeure concepts y force majeure clauses.

\section{LA FUERZA MAYOR COMO EVENTO IMPEDITIVO}

Lo que a veces se olvida es que la FM es un evento impeditivo, es decir, que el evento que califique como FM debe tornar imposible la prestación debida - “La forcé majeure peut être sommairement définie comme l'événement qui rend imposible la réalisation de la prestation promise" (Terré, Simler, Lequette y Chénedé, 2019, p. 810)—. El artículo 1315 del Código Civil también hace referencia a la imposibilidad "que impide la ejecución de la obligación". Por lo tanto, para poder determinar si la prestación se torna imposible, hay que ver cada caso en particular.

\section{Principio de vinculación del contrato y los eventos impeditivos}

Durante el desarrollo de la relación contractual, pueden sobrevenir vicisitudes que perturben o interfieran con la operación económica programada por las partes. Esto, obviamente, ocurre en los contratos de duración. Al respecto, Gallo (2002) señala lo siguiente:

Los riesgos de una mutación de las circunstancias tales de crear una diferencia entre la regulación contractual - por definición, estática e inmutable- y la realidad en continua evolución serán naturalmente mayores cuanto más largo sea el intervalo de tiempo que corre entre el momento de la conclusión del contrato y la ejecución del mismo. (p. 4) 
En el caso de sucesos sobrevinientes, el legislador parece disciplinar el problema a través de la regla de la "fuerza de ley" del contrato, que, en el caso del Código Civil peruano, se recoge en el primer párrafo del artículo 1361, que establece lo siguiente: "Los contratos son obligatorios en cuanto se haya expresado en ellos". Es el pacta sunt servanda de los romanos: las partes de un contrato deben cumplir lo acordado y de la forma acordada. De la fórmula "fuerza de ley" en realidad fluye la idea de "vínculo contractual", es decir, de la sujeción de las partes a los efectos del contrato'.

Uno de los significados que se desprenden del principio de vinculación contractual (pacta sunt servanda) impone a las partes cumplir las obligaciones contractualmente asumidas, bajo cualquier circunstancia. ¿El deudor sigue obligado a cumplir incluso si la prestación se torna imposible sobrevinientemente por causa no imputable a las partes?

En el Código Civil peruano, se otorga relevancia a algunas vicisitudes (hechos, eventos o circunstancias) sobrevinientes a la conclusión del contrato cuya gravedad es considerada tal como para justificar una limitación a la operatividad de la regla de la "fuerza de ley": es el caso de la imposibilidad sobreviniente y de la excesiva onerosidad de la prestación.

Corresponde, entonces, distinguir, como regla general, los eventos sobrevinientes impeditivos de los no impeditivos. La imposibilidad sobreviniente supone el acaecimiento de un evento impeditivo, mientras que la excesiva onerosidad de la prestación supone un evento no impeditivo.

\section{La imposibilidad sobreviniente de la prestación por causa no imputable a las partes ${ }^{2}$}

La imposibilidad sobreviniente es una condición previa para la FM - “impide la ejecución de la obligación" (Antonmattei, 1992) - En efecto, si el evento no impide al deudor la ejecución de la prestación, este no podrá invocar FM para excusarse del incumplimiento. Este es el caso de las obligaciones genéricas; su ejecución nunca se torna imposible (genus nunquam perit) $)^{3}$ lo genérico no perece. Ello ocurre con las obligaciones dinera-

1 Temporalmente puede no darse la coincidencia entre vínculo y efectos; en tal sentido, puede subsistir el vínculo aún si el contrato no produce todos sus efectos, como ocurre, por ejemplo, en el contrato sujeto a condición suspensiva.

2 Gran parte de las ideas de este punto ya fueron expuestas en Barchi (2011).

3 Artículo 1146 del Código Civil: “Antes de la individualización del bien, no puede el deudor eximirse de la entrega invocando la pérdida sin su culpa". En realidad, el aforismo genus nunquam perit no representa una regla de las obligaciones genéricas que excluya a priori que estas se puedan tornar imposibles.

Al igual que en la obligación de dar bien cierto en las obligaciones genéricas (amplia o limitada), la imposibilidad de la prestación se produce por la pérdida del bien debido. Lo que ocurre es que, en el caso de las genéricas, la imposibilidad exige la pérdida de todas las cosas del género.

Lo que ocurre en las genéricas es que la imposibilidad tendrá un diverso alcance en orden a las posibilidades del deudor. Así, por ejemplo, la obligación genérica amplia puede devenir imposible 
rias, dado que la impotencia financiera (la falta de recursos) no se considera una excusa frente al incumplimiento (Bianca, 1993).

De acuerdo con el artículo 1315 del Código Civil: "Caso fortuito o fuerza mayor es la causa no imputable [...] que impide la ejecución de la obligación" [cursivas añadidas]. En otras palabras, la FM es el evento que torna imposible sobrevinientemente la ejecución de la prestación por causa no imputable a las partes.

Se suele señalar que la imposibilidad debe ser absoluta y objetiva. La imposibilidad de la prestación se dice objetiva cuando no solo es imposible para el particular deudor, sino también para cualquier otra persona en su lugar y en las mismas circunstancias. La objetividad de la imposibilidad determina que son irrelevantes las causas que conciernen solo a la persona del deudor, es decir, son irrelevantes los casos de imposibilidad meramente subjetiva. La imposibilidad subjetiva es la que se personaliza en el deudor.

Como señala Trimarchi (2008), la imposibilidad "es manifiestamente una noción objetiva, independiente de dificultades, impedimentos subjetivos o circunstancias desafortunadas relativas a la programación y a la organización del deudor".

La imposibilidad subjetiva tendrá lugar en los casos en los cuales existe una conexión estrecha e indisoluble con la persona del deudor, como ocurre comúnmente en el caso de los contratos intuitu personae (lacono, 2008). En tales supuestos, dado que el cumplimiento se halla estrechamente ligado a las cualidades personales de deudor ${ }^{4}$, no pueden dejar de asumir relevancia las vicisitudes que interesan directamente a dicho deudor. Los eventos que afectan física o psíquicamente a la persona del deudor y lo privan de la aptitud de ejecutar la prestación pueden calificar como FM cuando se trata de prestaciones de carácter personal (Bianca, 1994).

La imposibilidad debe ser absoluta en el sentido de que "el impedimento no puede ser superado de ninguna manera, cualquiera sea el esfuerzo que el deudor pueda hacer" (Caringella y De Marzo, 2007, p. 372). El carácter "absoluto" de la imposibilidad niega la relevancia de la simple difficultas praestandi.

\section{La causa no imputable}

De acuerdo con el artículo 1315 del Código Civil: “Caso fortuito o fuerza mayor es la causa no imputable [cursivas añadidas] [...] que impide la ejecución de la obligación". La noción de "causa no imputable" se relaciona, pues, con la imposibilidad sobreviniente. Podría sostenerse, entonces, que la FM es el evento que torna imposible sobrevinientemente

por resultar imposible legalmente la entrega -el género queda fuera del comercio-. Al respecto, véase Sánchez Calero (1980).

4 "Artículo 1149.- La prestación puede ser ejecutada por persona distinta al deudor, a no ser que del pacto o de las circunstancias resultara que esta fue elegida por sus cualidades personales". 
la ejecución de la prestación: imposibilidad por causa no imputable a las partes sería igual a FM.

En nuestro Código Civil, al hablar de "causa no imputable", no se exime de tomar en consideración la debida diligencia requerida al deudor y este es, precisamente, el fundamento de la responsabilidad de aquel, conforme a lo previsto en el artículo 1314 del Código Civil: "Quien actúa con la diligencia ordinaria requerida, no es imputable por la inejecución de la obligación o por su cumplimiento parcial, tardío o defectuoso" ${ }^{5}$.

Al respecto, Osterling (2007) señala lo siguiente:

El artículo 1314 prescribe que quien actúa con la diligencia ordinaria requerida, no es imputable por la inejecución de la obligación o por su cumplimiento parcial, tardío o defectuoso. La norma [el artículo 1315] se refiere a la causa no imputable, es decir, a la ausencia de culpa, como concepto genérico exoneratorio de responsabilidad. (p. 223)

En síntesis, la FM es un evento no previsible ni superable con la diligencia debida (es, pues, una superior force).

Así, por ejemplo, califican como FM las prohibiciones establecidas por actos de la autoridad pública (hechos del príncipe): factum principis ${ }^{6}$. Adviértase que, en estos casos, en estricto, estamos fuera de la idea objetiva de imposibilidad. De hecho, el acto prohibido por la autoridad pública es posible, pero esto importa un costo: la violación de una norma imperativa. Ello, sin embargo, excede la debida diligencia del deudor. En estos casos, la promulgación del Decreto Supremo 044-2020-PCM “podría" calificar como FM.

En el caso de los eventos de la naturaleza (hechos de Dios) ${ }^{7}$, como terremotos, aluviones, epidemias, etcétera, es preciso, también, determinar si constituyen o no eventos impeditivos que superan el esfuerzo debido diligente del deudor. Por ejemplo,

5 El Código Civil francés recurría a un parámetro (estándar) objetivo medio; así, establecía que para cumplir sus obligaciones el deudor debía usar la diligencia de un "buen padre de familia".

Parámetro (estándar) objetivo medio = para cumplir sus obligaciones, el deudor debe usar la diligencia de un "buen padre de familia". El Código Civil francés (antes de la modificación del 2016 - Loi 2014-873-) lo eliminó por su carácter sexista y lo sustituyó por el estándar de la "persona razonable", con lo que se aproximó al criterio anglosajón del reasonable man.

Del artículo 1320 del Código Civil se entiende que el deudor ha de actuar con la "diligencia ordinaria exigida por la naturaleza de la obligación y que corresponda a las circunstancias de las personas, del tiempo y del lugar".

6 La ICC Force Majeure Clause 2003 señala entre los eventos: “Act of authority whether lawful or unlawful, compliance with any law or governmental order, rule, regulation or direction, curfew restriction, expropriation, compulsory acquisition, seizure of works, requisition, nationalization".

7 La ICC Force Majeure Clause 2003 señala entre los eventos: “Act of God, plague, epidemic, natural disaster such as but not limited to violent storm, cyclone, typhoom, hurricane, tornado, blizzard, earthquake, volcanic activity, landslide, tidal wave, tsunami, flood, damage or destruction by lightning, drought". 
el fenómeno de El Niño genera fuertes lluvias que afectan, principalmente, la costa del Perú. De acuerdo con las investigaciones realizadas, se reporta desde el año 1892. Queda claro que no es un evento imprevisible y que, por lo tanto, debería ser tenido en cuenta en la construcción de obras de infraestructura.

Se podría sostener, teniendo en cuenta el artículo 1972 del Código Civil ${ }^{8}$, que la causa no imputable, además de la FM, comprende el hecho determinante de tercero y el hecho del acreedor. Hay que considerar que el hecho de tercero se puede poner de manifiesto bajo tres aspectos (Bianca, 1994) y no todos ellos serán excusa del deudor frente al incumplimiento: i) la falta de provisión de los medios necesarios al deudor para que este pueda cumplir su obligación - por ejemplo, el constructor no puede ejecutar la prestación porque su proveedor incumple entregarle los materiales-; ii) la intervención del tercero que priva al deudor del bien debido o de los medios necesarios para cumplir - por ejemplo, ladrones sustraen el bien debido al acreedor-, y iii) constreñir el incumplimiento - por ejemplo, una banda criminal advierte al contratista que no puede continuar con la ejecución de la obra sin pagar un cupo-.

La diligencia debida impone al deudor tomar las medidas necesarias contra los incumplimientos o retardos de sus proveedores y prevenir hechos de terceros sobre bienes en su esfera de control, dentro de los límites de la debida diligencia. Por otro lado, hay causa no imputable cuando la amenaza o violencia asume extremos de seriedad y gravedad.

El hecho del acreedor sí constituye una excusa del deudor frente al incumplimiento; es una "causa no imputable al deudor". Al respecto, debe tenerse en cuenta que la imposibilidad definitiva de la prestación puede producirse por "causa imputable al acreedor"9 o "por culpa del acreedor"10.

Si la imposibilidad de la prestación se produce por causa imputable al acreedor, este asume el riesgo. Así, el segundo párrafo del artículo 1432 del Código Civil establece lo siguiente: "Cuando la imposibilidad sea imputable al acreedor, el contrato queda resuelto de pleno derecho. Sin embargo, dicho acreedor deberá satisfacer la contraprestación".

En este caso, la relación obligatoria se extingue (ex artículo 1316 del Código Civil). El deudor, cuya prestación deviene imposible por el hecho del acreedor, se libera de la obligación y es exonerado de la responsabilidad por la no ejecución de la prestación.

8 “En los casos del artículo 1970, el autor no está obligado a la reparación cuando el daño fue consecuencia de caso fortuito o fuerza mayor, de hecho determinante de tercero o de la imprudencia de quien padece el daño".

9 El artículo 1432 del Código Civil hace mención a la causa imputable ("Cuando la imposibilidad sea imputable al acreedor").

10 Así, por ejemplo, el artículo 1155 menciona la imposibilidad "por culpa del acreedor". 
De acuerdo con el artículo 1432 del Código Civil, el contrato queda resuelto automáticamente ("de pleno derecho"), pero el deudor mantiene el derecho a la contraprestación. Hay aquí una contradicción.

En efecto, algunos autores ${ }^{11}$ sostienen que la imposibilidad sobreviniente imputable al acreedor no conlleva la resolución del contrato; sino que este subsiste y, a pesar de que el deudor se libera de la ejecución de la prestación a su cargo que se tornó imposible, tendrá derecho a recibir la contraprestación. Adviértase, pues, que el pago de la contraprestación se da en la medida en que el contrato subsiste. Otro sector considera que el contrato se resuelve automáticamente, pero que el deudor tiene derecho al resarcimiento de la lesión del interés positivo ${ }^{12}$. En ambos casos, el deudor se ve eximido de responsabilidad por el incumplimiento o por el retardo en el que incurre.

¿Es posible que el acreedor alegue FM en su carga de colaboración? Al respecto, ha de tenerse en cuenta que la mora del acreedor es inculpata; por lo tanto, el acreedor no puede alegar FM para eximirse de su carga de colaboración. Es cierto que el artículo 1338 del Código Civil hace referencia a "sin motivo legítimo"; pero la doctrina, de manera unánime, reconoce que se refiere al hecho de que el acreedor puede negarse justificadamente a recibir el bien que el deudor le ofrece cuando no se dan los requisitos objetivos de regularidad del pago (identidad, indivisibilidad e integridad).

\section{LAS CONSECUENCIAS DE LA IMPOSIBILIDAD SOBREVINIENTE POR CAUSA NO IMPUTABLE A LAS PARTES}

La imposibilidad sobreviniente puede ser definitiva o temporal.

\section{Las consecuencias de la imposibilidad definitiva por causa no imputable a las partes}

Al sobrevenir un obstáculo que impide la ejecución de una prestación, surgen problemas que inciden en el riesgo relativo al evento sobrevenido. Estos problemas pueden ser encuadrados en una doble perspectiva: en primer lugar, con referencia a la asignación del riesgo al interno de la relación obligatoria y, en segundo lugar, cuando la relación obligatoria es de fuente contractual, con referencia a la asignación de los riesgos entre las partes del contrato (Cabella, 2002).

11 Al respecto, véase Cabella (2002, pp. 117-118) y Delfini (2003, p. 49). Cabe advertir que el Código Civil italiano no disciplina las consecuencias de la imposibilidad sobreviniente por causa imputable al acreedor.

12 El § 324 del BGB no habla de resolución; señala "que la primera parte mantiene su pretensión a la contraprestación" y añade lo siguiente: "Debe, sin embargo, deducir lo que se ahorra como consecuencia de la liberación de la prestación, o lo que adquiere o intencionalmente omita adquirir por un uso ulterior de su trabajo". Luego de la modificación, el § 326 recoge el texto citado. 
Asignar el riesgo al interno de la relación obligatoria supone establecer si el impedimento vale para liberar al deudor (de la prestación imposible) del cumplimiento de su obligación (riesgo a cargo del acreedor) o si, en cambio, el deudor sigue obligado a cumplir y, de no hacerlo, resarcir los daños y perjuicios que sufra el acreedor (riesgo a cargo del deudor).

Asignar el riesgo entre las partes del contrato constituye una operación más compleja, que tiende a determinar si al sobrevenir el impedimento de la ejecución de una prestación ello supone la extinción del vínculo contractual o si, en cambio, i) lo deje subsistente e inalterado, o ii) lo deje subsistir solo con modificaciones.

Respecto a los contratos con prestaciones recíprocas, el riesgo estará a cargo del deudor de la prestación impedida cuando el contrato sobreviva inalterado o cuando al extinguirse el vínculo contractual surja la obligación a cargo de la parte deudora. Los riesgos se repartirán cuando el contrato esté sujeto a modificaciones o cuando el vínculo contractual se extinga y al extinguirse la obligación del deudor (riesgo de la prestación a cargo del deudor) se extinga también la contraprestación (riesgo de la contraprestación a cargo de la otra parte). Todo el riesgo será a cargo de la parte acreedora, si la parte deudora se libera manteniendo el derecho a la contraprestación.

El artículo 1316 del Código Civil se refiere a la única consecuencia que se genera de la imposibilidad - definitiva-sobreviniente de la prestación por causas no imputables a las partes en el caso de un contrato con prestación a cargo de una sola de las partes: la extinción de la relación obligatoria y la consecuente liberación del deudor.

Pero ¿cuáles son las consecuencias cuando estamos frente a un contrato con prestaciones recíprocas? Es decir, cuando existen prestaciones a cargo de ambas partes y una de ellas se torna imposible de manera sobreviniente. La respuesta se encuentra en los siguientes libros del Código Civil: en el libro VI ("Las obligaciones"), lo encontramos a propósito de las relaciones obligatorias con prestación de dar bien cierto (artículo 1138 del referido código), de las relaciones obligatorias con prestación de hacer (artículos 1154, 1155 y 1156 del código mencionado) y en las relaciones obligatorias con prestación de no hacer (artículo 1160 del código aludido, que remite a los artículos 1154, primer párrafo, 1155 y 1156). En el libro VII lo encontramos en la sección primera ("Contratos en general") respecto a los contratos con prestaciones recíprocas (artículos 1431, 1432 y 1433 del Código Civil). Al ocuparse del contrato de compraventa, se refiere a la transferencia del riesgo (artículos 1567, 1568, 1569 y 1570 del acotado código).

¿Qué sucede cuando la imposibilidad se produce por causa no imputable a las partes? En este caso, será de aplicación el artículo 1431 del Código Civil, que señala lo siguiente: 
En los contratos con prestaciones recíprocas, si la prestación a cargo de una de las partes deviene imposible sin culpa de las contratantes, el contrato queda resuelto de pleno derecho [cursivas añadidas]. En este caso, el deudor liberado el derecho a contraprestación y debe restituir lo que ha recibido.

Empero, las partes pueden convenir en que el riesgo esté a cargo del acreedor.

\section{¿Y si la prestación deviene imposible temporalmente por causa no imputable a las partes?}

Si se tiene en cuenta que la FM es la causa no imputable, entonces el análisis se centrará en analizar el caso de la imposibilidad sobreviniente temporal por FM. Este es el supuesto más frecuente: el impedimento temporal.

Al respecto, el artículo 1316 del Código Civil establece lo siguiente:

La obligación se extingue si la prestación no se ejecuta por causa no imputable al deudor.

Si dicha causa es temporal, el deudor no es responsable por el retardo mientras ella perdure [cursivas añadidas]. Sin embargo, la obligación se extingue si la causa que determina la inejecución persiste hasta que el deudor, de acuerdo al título de la obligación o a la naturaleza de la prestación, ya no se le pueda considerar obligado a ejecutarla; o hasta que el acreedor justificadamente pierda interés en su cumplimiento o ya no le sea útil.

La imposibilidad temporal se caracteriza por la incerteza en las vicisitudes de la relación obligatoria, la cual puede desembocar en un resultado positivo - por cesación del impedimento- o negativo - como consecuencia de pasar de un impedimento provisorio a uno definitivo-, o bien en un resultado incierto, a causa de una prolongación por tiempo indeterminado del impedimento temporal (Fondrieschi, 2012).

Ahora bien, si se trata de un contrato con prestaciones recíprocas, ¿qué sucede con la contraprestación? Pues el sinalagma que liga la prestación temporalmente imposible a contraprestación hace que esta última no sea debida, y una eventual pretensión de cumplimiento sería bloqueada por una excepción de incumplimiento (Cabella, 2002).

El artículo 1316 del Código Civil deja muchos vacíos en caso de impedimento temporal. Veamos:

a) Algunos autores consideran que en este caso la FM tiene un "efecto suspensivo"13 y esa suspensión puede suponer: i) la extensión del plazo para la ejecución del

13 Véase Fontaine y De Ly (2013, p. 462), Delfini (2003, p. 35), Roppo (2011, p. 1007) y Fondrieschi (2012, p. 309). 
contrato por el mismo tiempo durante el cual la ejecución estuvo suspendida o ii) la no extensión de la duración del contrato.

b) La suspensión puede generar problemas en los contratos de abastecimiento; así, la pregunta es si el comprador está facultado para realizar una operación de reemplazo y obtener las provisiones de un tercero (Fontaine y De Ly, 2013).

c) ¿Qué pasa con los costos en los que las partes incurrieron durante la suspensión? Fontaine y De Ly (2013) indican lo siguiente:

Los costos pueden ser considerables: gastos de almacenamiento para mercaderías cuya entrega ha sido suspendida, gastos de mantener temporalmente al personal a la espera, etc. Tales gastos están ligados a la obligación de utilizar todos los medios posibles para asegurar la ejecución de lo que queda del contrato tan pronto como sea posible.

Las cláusulas de FM generalmente establecen que no habrá compensación entre las partes por estos costos.

d) El Código Civil tampoco impone a las partes la obligación de reanudar la ejecución del contrato inmediatamente. Sin embargo, en este caso creemos que dicha obligación se genera sobre la base del principio de buena fe.

La duración del evento de FM ("FM prolongada") puede tener como efecto privar sustancialmente a una o ambas partes contratantes de las expectativas razonables que legítimamente cabía esperar a tenor del contrato; correspondería otorgar a cada parte la facultad de terminar el contrato mediante una notificación realizada a la otra parte. Así, el efecto suspensivo se convierte en un efecto extintivo que opera de pleno derecho.

\section{LA FUERZA MAYOR COMO EXIMENTE DE RESPONSABILIDAD: ¿FRACTURA CAUSAL O EXCUSA FRENTE AL INCUMPLIMIENTO?}

De Trazegnies, comentando el artículo 1372 del Código Civil relativo a la responsabilidad extracontractual (rectus lesión de un interés jurídicamente protegido en la vida de relación), señala que uno de los casos en los cuales se rompe el vínculo causal entre el causante aparente y la víctima es la FM. En tal caso, al no existir nexo causal, no hay tampoco responsabilidad (1999). Por ello, la FM es considerada un supuesto de fractura causal.

En el caso de la lesión del interés crediticio (responsabilidad contractual) la situación es distinta ${ }^{14}$. La prestación está dirigida a satisfacer el interés del acreedor, que no

14 Gran parte de las ideas de este punto ya fueron expuestas en Barchi (2018). 
es otra cosa que la necesidad de bienes y servicios ${ }^{15}$. Se produce una lesión del interés crediticio cuando el comportamiento del deudor, apreciado desde una óptica objetiva, independiente de cualquier valoración o calificación de dicho comportamiento, no se ajusta al programa de prestación (Díez-Picazo, 2008).

La regla general de la responsabilidad civil establece que, para imponer a alguien la obligación de reparar el daño, es necesario que este lo haya causado (Infantino, 2015, p. 86). Si bien es condición necesaria, no es condición suficiente. Así lo explica Honoré (2010): el ser causante del daño no es una condición necesaria ni suficiente para ser considerado responsable del daño por la ley. No es una condición necesaria porque la ley puede hacer responsable a una persona por el daño causado por otra, por animales, por objetos inanimados, por procesos, entre otros. En estos casos, a la persona se le atribuye responsabilidad no por haber causado el daño, sino por haber asumido el riesgo de que otra persona, animal, cosa o proceso lo cause. El riesgo puede ser voluntariamente asumido o impuesto por la ley.

En efecto, por un lado, los factores de atribución delimitan ulteriormente el radio de acción; así, no siempre quien ha causado un daño responde. Conforme a los artículos 1314 (responsabilidad por lesión al interés crediticio) y 1969 (responsabilidad por lesión de un interés jurídicamente protegido en la vida de relación) del Código Civil, además de la causalidad, se requiere la concurrencia de la culpa ${ }^{16}$.

En el sistema de la responsabilidad civil, la causalidad cumple una doble finalidad: imputa al responsable el hecho ilícito ("causalidad de hecho" o cause in fact, en el derecho anglosajón) y establece la entidad de las consecuencias perjudiciales del hecho que se traducen en el daño resarcible - "causalidad jurídica"- (Franzoni, 2004). En otras palabras, la "causalidad de hecho" se refiere a la determinación del hecho fuente de la responsabilidad y la "causalidad de jurídica" al problema de la selección de las consecuencias dañosas resarcibles.

En lo que respecta a la responsabilidad por lesión del interés crediticio, a diferencia de lo que ocurre en el caso de la responsabilidad por lesión de un interés jurídicamente protegido en la vida de relación (responsabilidad extracontractual), no es un problema la búsqueda del responsable por cuanto la existencia de la relación obligatoria simplifica la individualización del sujeto llamado a responder el hecho dañoso: el deudor (Pinori, 1999). En el mismo sentido, Carbone (2009) señala que en la responsabilidad

15 Al respecto, Nicolò (2008) señala lo siguiente: “El concepto de interés no es de por sí un concepto jurídico, sino que es un prius respecto al Derecho, un dato preexistente al ordenamiento, que será tomado de la Economía para ser más o menos considerado. Para definir el concepto de interés, es necesario, por ende, recurrir a los conceptos de la ciencia económica" (p. 106).

El artículo 1970 del Código Civil recoge la responsabilidad objetiva. 
contractual el sujeto responsable ya es conocido e identificado, y es el deudor que no ha ejecutado la prestación debida.

En efecto, el artículo 1321 del Código Civil ya individualiza al responsable del daño en la persona del deudor, "quien no ejecuta sus obligaciones". Por lo tanto, en el caso de la responsabilidad por lesión del interés crediticio, en principio, no se recurre a la causalidad para imputar el hecho dañoso a un sujeto (causalidad de hecho). Un asunto distinto es la delimitación del daño resarcible que el deudor que no ejecuta la prestación debida habrá de asumir (causalidad jurídica).

Por ende, en la responsabilidad por lesión del interés crediticio no hay fractura causal; el deudor incumplió su prestación, pero tiene una excusa frente a su incumplimiento: la FM.

\section{¿QUÉ SIGNIFICA QUE LA FUERZA MAYOR SEA UNA EXCUSA FRENTE AL INCUMPLIMIENTO?}

El artículo 1317 del Código Civil establece lo siguiente:

El deudor no responde de los daños y perjuicios resultantes de la inejecución de la obligación, o de su cumplimiento parcial, tardío o defectuoso, por causas no imputables, salvo que lo contrario esté previsto expresamente por la ley o por el título de la obligación.

El deudor no responde por el incumplimiento cuando la prestación a su cargo deviene definitiva y totalmente imposible por causas no imputables a las partes.

En el caso de la imposibilidad temporal, conforme al artículo 1316 del Código Civil, "el deudor no es responsable por el retardo mientras ella perdure".

Podemos concluir, entonces, que el deudor no responde por la lesión del crédito (incumplimiento o retardo) cuando esta se produce por causas que no son superables por el deudor actuando con la diligencia ordinaria. Así, por ejemplo, un terremoto (caso fortuito) constituye un supuesto de causa no imputable solo si el deudor previó las medidas de prevención normalmente adecuadas con base en la común experiencia o la técnica profesional relativa al tipo de la prestación (Bianca, 1994). Como puede apreciarse, la imposibilidad sobreviniente por causa no imputable a las partes constituye una excusa frente al incumplimiento (artículo 1317 del Código Civil).

¿Qué significa que el deudor tenga una excusa frente a su incumplimiento? Veamos.

La "inejecución" de la prestación, sea en la hipótesis de incumplimiento o en la de retardo, puede generar daños a ambos contratantes: no solo al acreedor, sino también al deudor. En efecto, Trimarchi (2010) refiere lo siguiente: 
El acreedor de la prestación no cumplida puede, por una parte, haber pagado la contraprestación contractual, haber realizado gastos, asumido obligaciones y desatendido ocasiones alternativas confiando en conseguir la prestación que le es debida: gastos y daños que corresponden a su interés negativo (y representan su daño a la confianza); por otra parte, él ve frustrada la espera de conseguir el valor de la prestación que le era debida y los provechos que se habrían derivado, que corresponden a su interés positivo (y representan su daño por el incumplimiento). Y añade: En cuanto al deudor, si el incumplimiento implica para él la pérdida del derecho a la contraprestación, él ve frustrada la espera de recibirla y de conseguir los provechos que habría podido obtener, y ve faltar la cobertura que esta habría podido proporcionarle para los gastos eventualmente afrontados para preparar el cumplimiento. (p. 4)

Cuando se dice que el deudor es responsable, significa que asume los daños de la inejecución: los propios y los del acreedor, y queda obligado a pagarle la indemnización de daños y perjuicios. Cuando se menciona que el deudor no responde por causa no imputable, entonces cada parte asume sus propios daños.

La FM se entiende como una excusa al incumplimiento del deudor debido a un impedimento más allá del control de aquel cuyas consecuencias no podría haber evitado o superado. Las características del impedimento son las siguientes: i) debe superar la esfera de control del deudor, lo que supone que este ha de soportar el riesgo de su propia actividad; ii) no habría podido ser tomado en consideración al tiempo de la celebración del contrato, es decir, un hombre razonable no podía haberlo previsto, y iii) el deudor debe probar que no habría podido evitarlo o no habría podido superarlo, lo cual depende de circunstancias concretas (es insuperable). No se puede esperar que el deudor tome precauciones desproporcionadas respecto al riesgo para impedir el evento.

\section{A MODO DE COLOFÓN: EL ACUERDO DISTINTO}

Como se ha podido advertir, el artículo 1315 del Código Civil no es una norma imperativa. Ello permite a las partes recurrir a las cláusulas de FM dejando de lado referirse a un "evento extraordinario, imprevisible e irresistible que impide la ejecución de la obligación" y hacerlo, por ejemplo, a "an impediment beyond the debtor's control and if the debtor could not reasonably be expected to have avoided or overcome the impediment or its consequences".

Pero no solo eso. Debemos tener presente que una de las funciones de los contratos -principalmente en los de duración- es la asignación de los riesgos entre las partes involucradas. El contrato es un acto de previsión y, por ende, las partes al celebrarlo se proyectan hacia el futuro. Es decir, la previsión es la esencia del contrato. 
A través de la previsión, las partes asignan los riesgos. En efecto, al prever para el futuro la ocurrencia de un evento, se distribuyen las consecuencias de este. La adopción de un tipo contractual supone una distribución convencional del riesgo de manera implícita (Delfini, 1999, p. 33). Esto comprende también el hecho de incluir un determinado tipo de cláusula17.

Las partes, frente a un evento "extraordinario, imprevisible e irresistible que impide la ejecución de la obligación" o "an impediment beyond the debtor's control", podrían asignar los riesgos de manera diferente a lo que hace el Código Civil por defecto.

\section{REFERENCIAS}

Antonmattei, P. (1992). Contribution à l'étude de la force majeure [La contingencia contractual] (t. 220). París: Bibliothèque de Droit Privé.

Barchi, L. (2011). La "teoría del riesgo" o, mejor dicho, la atribución del riesgo en caso de imposibilidad sobreviniente de la prestación. Revista de Análisis Especializado de Jurisprudencia - RAE Jurisprudencia, 4(38), 73-86.

Barchi, L. (2018). ¿Quién ha sido? Algunas consideraciones sobre la causalidad y la imputación en materia de responsabilidad civil en el Código Civil peruano. En H. Campos y J. Gabriel (Coords.), Responsabilidad civil. De la comparación a la aplicación (pp. 83-123). Lima: Thémis Editorial Jurídica.

Bianca, M. (1993). Diritto civile [Derecho civil] (t. 4). Milán: Giuffrè.

Bianca, M. (1994). Diritto civile [Derecho civil] (t. 5). Milán: Giuffrè.

Cabella, L. (2002). Impossibilità sopravvenuta [Imposibilidad inesperada]. En F. Galgano (Ed.), Commentario del Codice Civile [Comentarios al Código Civil]. Bolonia: Zanichelli.

Carbone, V. (2009). Nesso di causalità e criteri di valutazione del danno contrattuale [Criterios de causalidad y evaluación del daño contractual]. En: A. Zoppini (Ed.), Diritto civile [Derecho civil] (VIII, t. I.). Milán: Giuffrè.

Caringella, F. y De Marzo, G. (2007). Manuale di diritto civile. II Le Obbligazioni [Manual de derecho civil. II Las obligaciones]. Milán: Giuffrè.

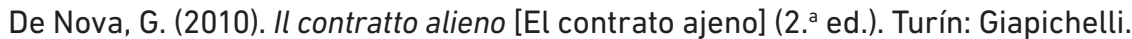

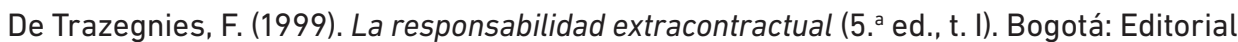
Temis.

17 Así, por ejemplo, incluyendo una cláusula de reajuste (artículo 1235 del Código Civil), para mantener la suma de dinero pactada en valor constante. Otro ejemplo es la incorporación de una cláusula take or pay en un contrato de suministro de gas natural. 
De Trazegnies, F. (2015). Artículo 1315. Caso fortuito o fuerza mayor. En C. Soto (Dir.), Tratado de responsabilidad civil contractual y extracontractual. Comentarios a las normas del Código Civil (vol. I). Lima: Instituto Pacífico.

Delfini, F. (1999). Autonomia privata e rischio contrattuale [Autonomía privada y riesgo contractual]. Milán: Giuffrè.

Delfini, F. (2003). Dell'impossibilità sopravvenuta. Artt. 1463-1466 [La imposibilidad suprimida. Artículos 1463-1466]. En F. Busnelli (Dir.), Il Codice Civile. Commentario [El Código Civil. Comentario]. Milán: Giuffrè.

Díez-Picazo, L. (2008). Fundamentos del derecho civil patrimonial (6. ${ }^{a}$ ed., vol. 2). Cizur Menor (Navarra): Civitas-Thomson Reuters.

Fondrieschi, A. (2012). L'impossibilità sopravvenuta per causa non imputabile al debitore [La imposibilidad sobrevenida por causa no imputable al deudor]. En R. Sacco (Comp.), Trattato di diritto civile (t. 4). Turín: UTET.

Fontaine, M y De Ly, F. (2013). La redacción de contratos internacionales. Análisis de cláusulas. Cizur Menor (Navarra): Civitas-Thomson Reuters.

Franzoni, M. (2004). L'illecito [El ilícito]. En Trattato della responsabilità civile. Milán: Giuffrè.

Gallo, P. (2002). Sopravvenienza contrattuale e problema di gestione del contratto [Contingencia contractual y problema de gestión de contratos]. Milán: Giuffrè.

Honoré, T. (2010). Causation in the law [Causalidad en la ley]. The Stanford Encyclopedia of Philosophy. Recuperado de https://archivos.juridicas.unam.mx/www/bjv/libros /8/3796/21.pdf

lacono, M. (2008). L'impossibilità sopravvenuta [La imposibilidad sobrevenida.] En P. Fava, Le obbligazioni. Diritto sostanziale e processuale [Obligaciones. Derecho sustantivo y procesal] (t. II). Milán: Giuffrè.

Infantino, M. (2015). El derecho comparado de la causalidad aquiliana. En C. Moreno (Coord.), Estudios sobre la responsabilidad civil. Lima: Ediciones Legales.

Katsivela, M. (2007). Contracts: force majeure concepts or force majeure clauses? [Contratos: ¿conceptos de fuerza mayor o cláusulas de fuerza mayor?]. Uniform Law Review, 12(1), 101-119.

Larroumet, C. (1993). Teoría general del contrato (vol. II). Bogotá: Editorial Temis.

Nicolò, R. (2008). Las situaciones jurídicas subjetivas. Advocatus, (012), 103-116. https:// revistas.ulima.edu.pe/index.php/Advocatus/article/view/2711

Osterling, F. (2007). Las obligaciones (8. ${ }^{a}$ ed.). Lima: Grijley.

Pinori, A. (1999). Il criterio legislativo delle conseguenze immediate e dirette [El criterio legislativo de consecuencias inmediatas y directas]. En G. Visintini y T. Arrigo, Risarcimento del danno contrattuale ed extracontrattuale [Resarcimiento del daño contractual y extracontractual]. Milán: Giuffrè. 
Roppo, V. (2011). Il contratto [El contrato]. En G. ludica y P. Zatti (Eds.), Trattato di diritto privato [Tratado de derecho privado]. Milán: Giuffrè.

Sánchez Calero, F. (1980). Las obligaciones genéricas. Revista de Derecho Privado, 64(1), 644-660.

Terré, F., Simler, P., Lequette, Y. y Chénedé, F. (2019). Droit Civil. Les obligations [Derecho civil. Las obligaciones] (12. ${ }^{a}$ ed.). París: Dalloz.

Trimarchi, P. (2008). Incentivi e rischi nella responsabilità contrattuale [Incentivos y riesgos en la responsabilidad contractual]. Rivista di Diritto Civile, 54(3), 341 y ss.

Trimarchi, P. (2010). Il contratto: inadempimento e rimedi [El contrato: incumplimientos y remedios]. Milán: Giuffrè.

\section{BIBLIOGRAFÍA}

Ambrosoli, M. (2002). La sopravvenienza contrattuale. Milán: Giuffrè.

Barchi, L. (2004). ¿Mora del acreedor? Necesidad de algunas precisiones. En F. Escobar, R. Morales, L. León y E. Palacios (Dirs.), Negocio jurídico y responsabilidad civil. Estudios en memoria del profesor Lizardo Taboada Córdova. Lima: Grijley.

Barchi, L. (2009). Algunas consideraciones sobre el receso en el Código Civil peruano: a propósito del artículo 1786. Advocatus, (19), 291-321.

Breccia, U. (1991). Le obbligazioni [La obligación]. En G. ludica y P. Zatti (Eds.), Tratati di diritto privato. Milán: Giuffrè.

Cattaneo, G. (1973). Mora del creditore [Mora del acreedor]. En A. Scialoja y G. Branca (Eds.), Commentario del Codice Civile [Comentarios del Código Civil]. Bolonia: Zanichelli.

De Nova, G. (2011). Il contratto ha forza di legge [El contrato tiene fuerza de ley]. En /l contratto. Dal contratto atipico al contratto alieno [El contrato. Del contrato atípico al contrato ajeno]. Padua: Cedam.

Espinoza, J. (2019). Derecho de la responsabilidad civil (9. a ed., t. 1). Lima: Instituto Pacífico.

Farnsworth, E. A. (2004). Contracts [Contratos] (4. ${ }^{\mathrm{a}}$ ed.). Nueva York: Aspen Publishers.

Fernández, A. (2006). Imputación objetiva en un caso de responsabilidad civil ex delicto: criterio de la provocación. Comentario a la STS, $2^{\text {a }}$, 26.9.2005. InDret. Revista para el Análisis del Derecho, (1). Recuperado de https://indret.com/ imputacion-objetiva-en-un-caso-de-responsabilidad-civil-ex-delicto-criteriode-la-provocacion/?edicion $=1.06$

Fernández Cruz, G. y León Hilario, L. (2004). Comentarios al artículo 1315 del Código Civil. En Código Civil comentado (t. VI). Lima: Gaceta Jurídica. 
Mezzanotte, F. (2009). Impossibilità per causa non imputabile al debitore [Imposibilidad por causa no imputable]. En N. Lipari y P. Rescigno, Diritto civile (vol. III). Milán: Giuffrè.

Ruscello, F. (2003). Istituzioni di diritto privato [Instituciones de derecho privado] (vol. 2). Milán: Giuffrè.

Visintini, G. (1987). Inadempimento e mora del debitore. Artt. 1218-1222 [Incumplimiento y mora del deudor. Artículos 1218-1222]. En P. Schlesinger (Dir.), Il Codice Civile. Commentario. Milán: Giuffrè. 